\title{
Intrapartum Cervical Laceration and Subsequent Pregnancy Outcomes
}

\author{
Luchin F. Wong, MD ${ }^{1,2}$ Jacob Wilkes, BS ${ }^{3,4}$ Kent Korgenski, MS 3,4 Michael W. Varner, MD ${ }^{1,2}$ \\ Tracy A. Manuck, MD ${ }^{1,2}$ \\ ${ }^{1}$ Department of Obstetrics and Gynecology, University of Utah, \\ Salt Lake City, Utah \\ 2 Department of Maternal-Fetal Medicine, Intermountain Healthcare, \\ Salt Lake City, Utah \\ ${ }^{3}$ Department of Pediatrics, University of Utah, Salt Lake City, Utah \\ ${ }^{4}$ Pediatric Clinical Program, Intermountain Healthcare, \\ Salt Lake City, Utah \\ Am J Perinatol Rep 2016;6:e318-e323. \\ Address for correspondence Luchin F. Wong, MD, Obstetrix Medical \\ Group, 1229 Madison Street, Suite 750, Seattle, WA 98104 \\ (e-mail: luchinwong@gmail.com).
}

Objective The objective of this study was to describe pregnancy outcomes, including cervical insufficiency and preterm birth, in the subsequent pregnancy following an intrapartum cervical laceration.

Study Design Retrospective cohort of women with their first two consecutive singleton pregnancies carried to $\geq 20^{0 / 7}$ weeks' gestation within a tertiary health care system from 2002 to 2012 . Cervical laceration cases were identified by ICD 9 codes and included if suture repair was required.

Results In this study, 55 women were confirmed to have a cervical laceration in the first delivery; 43 lacerations after vaginal delivery (VD) and 12 after cesarean delivery (CD). The median gestational age of the first delivery was $40^{0 / 7}$ weeks and the median birth weight 3,545 g; these did not differ between VD and CD. In the second pregnancy, 2 of 55 women (4.6\%) had a prophylactic cerclage placed; 1 carried to term and the other delivered at $35^{6 / 7}$ weeks. In total, four women (9.3\%) delivered the second pregnancy $<37$ weeks: three had a prior term VD and one had a prior 34 weeks VD. There was only one case of recurrent cervical laceration, occurring in the setting of vaginal deliveries. Conclusion Obstetric cervical lacerations are uncommon. Complications in the following pregnancy were low, despite lack of additional prophylactic cerclage use.
Cervical trauma, or damage to the integrity of the cervical stroma, has been commonly cited as a contributing factor for cervical insufficiency. ${ }^{1,2}$ Cervical trauma is most commonly acquired from cervical conization, loop electrosurgical excision, mechanical dilation during pregnancy termination, and obstetric lacerations. Several studies have documented an association among cervical conization, electrosurgical excisions, and dilation and curettage and an elevated risk of cervical insufficiency, preterm premature rupture of membranes (PPROM), and preterm birth (PTB). ${ }^{3-8}$ However, few reports characterize pregnancy outcomes following obstetric trauma. $^{9-11}$

Intrapartum cervical lacerations are traditionally thought of as occurring due to the delivery of the fetus through the cervix at the time of vaginal birth. However, cervical lacerations may also be noted at the time of cesarean delivery (CD), particularly when the cesarean is performed during the second stage of labor (either due to second-stage arrest or for fetal indications). Some investigators have proposed that either a low positioned or caudally extended cesarean received

May 12, 2016

accepted after revision

August 1, 2016
DOI http://dx.doi.org/

$10.1055 / \mathrm{s}-0036-1592198$. ISSN 2157-6998.
Copyright $\odot 2016$ by Thieme Medical

Publishers, Inc., 333 Seventh Avenue, New York, NY 10001, USA. Tel: +1(212) 584-4662.
License terms

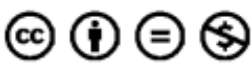


hysterotomy may inadvertently damage the cervix and increase the risk for cervical insufficiency and spontaneous PTB in subsequent pregnancy. ${ }^{2,9,10,12,13}$ However, this hypothesis is supported only by small case reports. ${ }^{10,14}$

The purpose of this study is to detail subsequent pregnancy outcomes following an intrapartum cervical laceration, focusing on future risk for cervical insufficiency and spontaneous PTB.

\section{Materials and Methods}

This is a retrospective cohort of women with their first two consecutive pregnancies carried to $20^{0 / 7}$ weeks or greater and delivered within the Intermountain Healthcare system (Salt Lake City, UT) between 2002 and 2012. Women with multifetal gestation or fetal anomalies/aneuploidy in either pregnancy were excluded. This study was approved by the Intermountain Healthcare Institutional Review Board.

Data were extracted from computerized point-of-care programs. The best obstetric estimate, utilizing last menstrual period and ultrasound parameters as appropriate, was used for dating criteria. ${ }^{15}$ Cases of cervical laceration in the first delivery were identified by ICD9 code, confirmed on chart review by a single physician researcher (L.F.W.), and included only if suture repair was documented. Outcomes of any intervening pregnancies $<20$ weeks were reviewed and details of the second pregnancy carried to $\geq 20^{0 / 7}$ weeks were extracted and evaluated. We specifically examined the incidence of PTB $<37$ weeks' gestation in the subsequent gestation, and evaluated the clinical "function" of the cervix by examining labor characteristics of the second pregnancy. Although we focused our data collection on prematurity and use of cervical cerclage, we also examined labor duration to account for the possibility of cervical stromal scarring and stenosis which could lead to prolonged labor. A portion of the original cohort of women identified with their first two consecutive pregnancies carried to $\geq 20^{0 / 7}$ weeks were reviewed to ensure that no women with cervical laceration in the first delivery were inappropriately excluded by ICD9 code identification. Data were analyzed using STATA version 12.0 (College Station, TX).

\section{Results}

Of 40,729 women with their first two consecutive pregnancies carried to $\geq 20^{0 / 7}$ weeks' gestation, 55 (0.14\%) were confirmed to have a cervical laceration requiring suture repair at the time of their first delivery. Demographic and baseline characteristics of our cohort are shown in - Table 1. The majority of cervical lacerations ( 43 of $55,78 \%$ ) were identified after vaginal delivery (VD); the remaining 12 were identified as cervical laceration secondary to hysterotomy extension at the time of $\mathrm{CD}$. The median gestational age of the first delivery was $40^{0 / 7}$ weeks (interquartile range [IQR]: $38^{3 /}$ ${ }^{7}-40^{2 / 7}$ ) and the median birth weight was $3,545 \mathrm{~g}$ (IQR: 3,233-3,967); these were similar between those with VD and CD (-Table 2). Five women had a PTB $<37$ weeks in their first pregnancy. Two women had a cervical cerclage placed during their first pregnancy. One woman had a history of an 18 weeks loss and subsequently presented at 21 weeks with cervical dilation at which time a rescue cerclage was placed. This pregnancy was complicated by PPROM and she delivered at $23^{5 / 7}$ weeks. In the following pregnancy, she had a prophylactic cerclage placed and was on vaginal progesterone. During this pregnancy, she was noted to have normal cervical length and delivered at $38^{2 / 7}$ weeks. The second woman also had a history of an 18 weeks loss but had a prophylactic cerclage placed in the subsequent pregnancy. This pregnancy was managed with vaginal progesterone and cervical length screening and delivered at $38^{0 / 7}$ weeks. In the following pregnancy, she again had a prophylactic cerclage placed, but went into spontaneous preterm labor, delivering at $35^{6 /}$ ${ }^{7}$ weeks by cesarean for breech presentation.

Among women with a cervical laceration noted at VD, 12 of 42 (28\%) delivered by forceps/vacuum, 4 of 42 (9.5\%) had a prolonged second stage $>3$ hours, and 21 of $42(50 \%)$ had an episiotomy. One additional woman had a cervical laceration noted vaginally when she was evaluated for arrest of descent,

Table 1 Maternal demographics and characteristics $(N=55)$

\begin{tabular}{|l|l|}
\hline Maternal characteristics & Value \\
\hline Median maternal age at first delivery (IQR), y & $24(21-27)$ \\
\hline Median maternal age at second delivery (IQR), y & $26(24-30)$ \\
\hline Caucasian, $n$ (\%) & $46(83.6)$ \\
\hline Private insurance, $n(\%)$ & $43(78.2)$ \\
\hline Tobacco use, $n(\%)$ & $1(2.1)$ \\
\hline Alcohol use, $n(\%)$ & $1(2.1)$ \\
\hline Illicit drug use, $n(\%)$ & $0(0.0)$ \\
\hline Median interpregnancy interval (IQR), y & $1.7(1.2-2.4)$ \\
\hline Interpregnancy interval $<18$ mo, $n(\%)$ & $23(41.8)$ \\
\hline Interpregnancy interval $<1 \mathrm{y}, n(\%)$ & $10(18.2)$ \\
\hline
\end{tabular}

Abbreviation: IQR, interquartile range. 
Table 2 Intrapartum characteristics of the first pregnancy $(N=55)$

\begin{tabular}{|c|c|c|c|}
\hline & $\begin{array}{l}\text { All } \\
N=55 \\
n(\%)\end{array}$ & $\begin{array}{l}\text { Cervical laceration } \\
\text { diagnosed after } \\
\text { vaginal delivery } \\
N=43 \\
n(\%)\end{array}$ & $\begin{array}{l}\text { Cervical laceration } \\
\text { diagnosed after } \\
\text { cesarean delivery } \\
N=12 \\
n(\%)\end{array}$ \\
\hline Median gestational age at delivery (IQR), wk & $40^{0 / 7}\left(38^{3 / 7}-40^{2 / 7}\right)$ & $39^{4 / 7}\left(38^{3 / 7}-40^{2 / 7}\right)$ & $40^{1 / 7}\left(38^{3 / 7}-40^{3 / 7}\right)$ \\
\hline Induction of labor with prostaglandins & $18(32.7)$ & $12(27.9)$ & $6(50.0)$ \\
\hline Mechanical (Foley bulb) induction & $1(1.8)$ & $1(2.3)$ & $0(0.0)$ \\
\hline Pitocin augmentation & $20(36.4)$ & $18(41.9)$ & $2(16.7)$ \\
\hline Precipitous delivery $<3 \mathrm{~h}$ & $0(0.0)$ & $0(0.0)$ & $0(0.0)$ \\
\hline Prolonged second stage $>3 \mathrm{~h}$ & $10(20.4)$ & $4(9.5)$ & $6 / 7(85.7)^{a}$ \\
\hline Vaginal delivery & $42(76.3)$ & 42 & $\mathrm{~N} / \mathrm{A}$ \\
\hline Operative delivery & 12 & 12 & $2^{\mathrm{b}}$ \\
\hline Forceps-assisted delivery & 9 & 9 & $2^{b}$ \\
\hline Vacuum-assisted delivery & 3 & 3 & $1^{\mathrm{b}}$ \\
\hline Episiotomy & $21(38.9)$ & $21(50.0)$ & $0(0.0)$ \\
\hline Cesarean delivery & $13(23.6)$ & $1^{\mathrm{c}}$ & 12 \\
\hline Chorioamnionitis & $1(1.8)$ & $0(0.0)$ & $1(8.3)$ \\
\hline Endometritis & $0(0.0)$ & $0(0.0)$ & $0(0.0)$ \\
\hline Median birth weight (IQR), g & $3,545(3,233-3,967)$ & $3,590(3,250-4,060)$ & $3,487(3,186-3,846)$ \\
\hline EBL (IQR), mL & $650(350-1,000)$ & $400(300-900)$ & $850(800-1,000)$ \\
\hline Maternal ICU admission & $0(0.0)$ & $0(0.0)$ & $0(0.0)$ \\
\hline
\end{tabular}

Abbreviations: EBL, estimated blood loss; ICU, intensive care unit; IQR, interquartile range; N/A, not applicable.

${ }^{a}$ Among the seven women who reached second stage of labor.

${ }^{b}$ Failed attempt at operative vaginal delivery.

${ }^{c}$ Cervical laceration was clearly documented as occurring during attempted vaginal delivery.

but then delivered by cesarean secondary to arrest of descent. Among women with a cervical laceration noted intraoperatively at the time of $C D, 7$ of 12 reached second stage of labor, and 6 of these were delivered for failed second stage. Two of these women had a failed operative delivery and ultimately required $C D$.

Outcomes of the subsequent pregnancy carried to $\geq 20$ weeks following an intrapartum cervical laceration in the first pregnancy are shown in - Table 3. Eight women had an intervening pregnancy $<20$ weeks. On review of maternal records, these losses were all noted to be early spontaneous miscarriages; none experienced a mid-trimester loss or cervical insufficiency. All women with a cervical laceration identified during $C D$ opted for a repeat CD. Four of 43 women who previously delivered vaginally underwent labor induction in their second pregnancy and the median duration of labor was 6.8 hours (IQR: 4.7-8.8); no induced labor lasted more than 21 hours from hospital admission to delivery. One woman (1.8\%) had recurrent cervical laceration, occurring after VD. Only two women (4.6\%) had a prophylactic cerclage placed in the second pregnancy carried to $\geq 20$ weeks and both had a cerclage placed in their initial pregnancy; there were no new cases of prophylactic cerclage use, nor were there any new cases of history- or ultrasound-indicated cerclages performed.
Four women (9.3\%) experienced a PTB $<37$ weeks in the second pregnancy and all four were spontaneous PTB; characteristics of their first and second pregnancies are shown in -Table 4. All four of these women had a history of intrapartum cervical laceration noted at VD. Three of these women had term VD in the first pregnancy and the fourth woman had $34^{5 / 7}$ weeks VD; all had at least one additional risk factor for PTB (-Table 4). No one in this group had a prolonged active stage or a prolonged second stage of labor $>3$ hours in their first or second deliveries.

With the exception of the two women who had a cervical cerclage in their first pregnancy carried to $\geq 20$ weeks, none of the women with a cervical laceration was documented to have had additional cervical length ultrasound screening, nor were they on progesterone in the subsequent pregnancy. None of these women was documented to have had short cervix during their routine mid-trimester ultrasound.

\section{Comment}

Cervical lacerations were uncommon in our cohort of women with two consecutive singleton, nonanomalous pregnancies within the Intermountain Healthcare system, occurring only in $0.14 \%$ of first deliveries. Although these women had clinically significant cervical lacerations requiring suture 
Table 3 Outcomes of the subsequent pregnancy following intrapartum cervical laceration

\begin{tabular}{|c|c|c|c|}
\hline & $\begin{array}{l}\text { All } \\
N=55 \\
n(\%)\end{array}$ & $\begin{array}{l}\text { Prior cervical laceration } \\
\text { diagnosed after } \\
\text { vaginal delivery } \\
N=43 \\
n(\%)\end{array}$ & $\begin{array}{l}\text { Cervical laceration } \\
\text { diagnosed after } \\
\text { cesarean delivery } \\
N=12 \\
n(\%)\end{array}$ \\
\hline $\begin{array}{l}\text { Median gestational age at delivery of } \\
\text { subsequent pregnancy (IQR), wk }\end{array}$ & $39^{1 / 7}\left(38^{3 / 7}-39^{3 / 7}\right)$ & $39.0\left(38^{2 / 7}-39^{2 / 7}\right)$ & $39^{3 / 7}\left(39^{0 / 7}-39^{4 / 7}\right)$ \\
\hline Cervical cerclage & $2(3.6)$ & $2(4.7)$ & $0(0.0)$ \\
\hline Induction of labor with prostaglandins & $4(7.3)$ & $4(9.3)$ & $0(0.0)$ \\
\hline Mechanical (Foley bulb) induction & $0(0.0)$ & $0(0.0)$ & $0(0.0)$ \\
\hline Pitocin augmentation & $16(29.1)$ & $16(37.2)$ & $0(0.0)$ \\
\hline Precipitous delivery $<3 \mathrm{~h}$ & $0(0.0)$ & $0(0.0)$ & $0(0.0)$ \\
\hline Prolonged second stage $>3 \mathrm{~h}$ & $0(0.0)$ & $0(0.0)$ & $0(0.0)$ \\
\hline Vaginal delivery & $42(77.8)^{\mathrm{a}}$ & $42(100.0)^{a}$ & $\mathrm{~N} / \mathrm{A}$ \\
\hline Operative delivery & $3(5.6)$ & $3(7.1)$ & $0(0.0)$ \\
\hline Forceps-assisted delivery & $0(0.0)$ & $0(0.0)$ & $0(0.0)$ \\
\hline Vacuum-assisted delivery & $3(5.6)$ & $3(7.1)$ & $0(0.0)$ \\
\hline Cesarean delivery & $14(25.9)$ & $2(4.8)$ & $12(100.0)^{b}$ \\
\hline Median birth weight (IQR), g & $3,500(3,210-3,725)$ & $3,490(3,042-3,730)$ & $3,550(3,299-3,695)$ \\
\hline $\mathrm{EBL}(\mathrm{IQR}), \mathrm{mL}$ & $400(300-600)$ & $300(250-400)$ & $800(600-800)$ \\
\hline
\end{tabular}

Abbreviations: $\mathrm{EBL}$, estimated blood loss; ICU, intensive care unit; IQR, interquartile range; N/A, not available.

${ }^{a}$ No information on mode of delivery for one woman.

${ }^{\mathrm{b}}$ All elected for repeat cesarean delivery, none desired a trial of labor after prior cesarean delivery.

repair, the rate of cervical insufficiency, PTB, and other obstetric complications in the subsequent pregnancy remained low, despite lack of additional prophylactic cerclage use, progesterone administration, or intensive pregnancy surveillance.

Our incidence of cervical laceration was similar to that reported by Melamed et al ( $0.16 \%)$. In their report, subsequent pregnancy outcomes for 42 women with a cervical laceration noted at the time of VD were similar to ours, as rates of second trimester abortion, PTB, and CD were not elevated.

In our cohort, only 4 of 55 women experienced PTB in the pregnancy immediately following an intrapartum cervical laceration. These were all late spontaneous PTB, ranging from $35^{4 / 7}$ to $36^{3 / 7}$ weeks. None of these subsequent PTB occurred after a cervical laceration identified at the time of $C D$. Although Melamed et $\mathrm{al}^{13}$ reported no PTB in the subsequent pregnancy in their cohort of women with vaginal cervical lacerations, and we believe our rate of PTB is not disproportionately higher but rather consistent with longitudinal studies that reported a PTB rate ranging from $6.5^{16}$ to $11.1 \%{ }^{17}$ in a general obstetric population following a first term delivery. Furthermore, three of these women had additional risk factors for PTB: interpregnancy interval $<18$ months, cerclage, and prior PTB.

Like Melamed et al, none of the women in our cohort had a second trimester loss or an intervening obstetric history concerning for cervical insufficiency. Similarly, we did not find an association between prior intrapartum cervical lacer- ation and induction of labor, prolonged active phase, or CD in the second pregnancy. In fact, our rate of induction (4 43, $9.3 \%$ ) is lower than the national rate of more than $20 \%{ }^{18-20}$ Likewise, our rate of primary $\mathrm{CD}$ ( 2 of $43,4.8 \%$ ) after a prior VD was lower than that reported by Melamed et al (10 of 42 , $23.8 \%)^{13}$

Our study has several limitations. Due to the retrospective nature of this study, the integrity of the data is dependent on the individual entering the data into computerized point-ofcare systems. Thus, our report may not capture all clinically relevant cases of cervical lacerations. However, most clinically significant cases of cervical laceration involve complication(s) that would likely be documented and captured by appropriate ICD9 codes. Likewise, cervical extension of the hysterotomy during $C D$ may be underreported. However, we believe that all clinically significant cases would be documented in the operative report with appropriate ICD9 coding and thus would be identified through our search. In addition, pregnancies that delivered $<20$ weeks' gestation were excluded from our analysis due to inconsistencies in delivery location and documentation in our database. This precluded our ability to capture a history of pregnancy loss at 16 to 20 weeks due to early cervical insufficiency both prior to the first delivery and following the first delivery, and is a clear limitation of this study. We were able to manually verify records of all women in our cohort, including records pertaining to possible pregnancy losses both prior to and subsequent to the first delivery and found that all eight women who had 


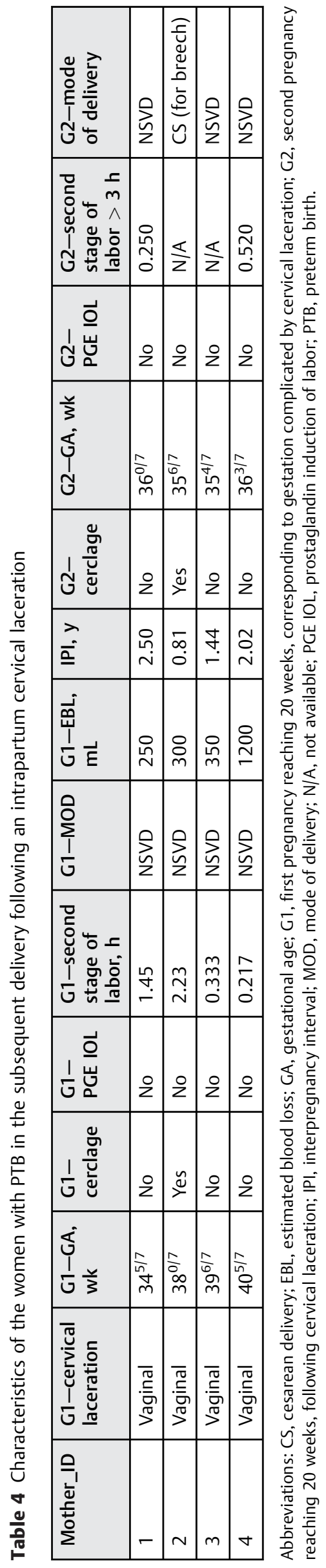

an intervening pregnancy loss had a first trimester loss. However, because the creation of our cohort was conditioned on having a second delivery $\geq 20$ weeks, we cannot accurately describe the true rate of pregnancy losses at $<20$ weeks or cervical insufficiency following a cervical laceration in the first successful pregnancy. Yet, the true rate of cervical insufficiency is likely to be very low since the majority of women would likely represent with a prophylactic or rescue cervical cerclage to achieve a successful outcome, and we did not identify any new cases of cerclage placement in our cohort. Finally, we only examined the subsequent pregnancy carried to $>20$ weeks following a cervical laceration. We have no data on any future pregnancy or pregnancies thereafter. However, we believe that any cervical damage that may have occurred at the time of cervical laceration would most severely impact the first pregnancy following the cervical laceration.

There are also numerous strengths to this study. Importantly, this is one of the largest reports of subsequent pregnancy outcomes for women with an intrapartum cervical laceration. Furthermore, our report stratifies by etiology: VD or $\mathrm{CD}$. We were able to identify detailed antepartum and intrapartum information regarding the first two consecutive pregnancies carried to at least 20 weeks' gestation allowing us to assess whether cervical ripening, protracted labor, or $\mathrm{CD}$ in the second delivery was increased in this cohort.

In conclusion, these data suggest that cervical lacerations are not associated with an increase in need for cervical cerclage placement, PTB, protracted labor, CD, or cervical laceration in the subsequent pregnancy. Thus, women with a history of a cervical laceration and no other risk factor for preterm delivery are unlikely to benefit from deviation from routine prenatal and intrapartum care.

Notes

Since the study was conducted, Dr. Wong has moved to Obstetrix Medical Group (Seattle, WA) and Dr. Manuck has moved to the Division of Maternal-Fetal Medicine, Department of Obstetrics and Gynecology, University of North Carolina at Chapel Hill (Chapel Hill, NC).

\section{Acknowledgments}

Research reported in this publication was supported by the NIH under award number 1K23HD067224, and NCATS/ NIH 8UL1TR000105, and the National Center for Advancing Translational Sciences of the National Institutes of Health under award number 1UL1TR001067. The content is solely the responsibility of the authors and does not necessarily represent the official views of the $\mathrm{NIH}$.

\section{References}

1 Kristensen J, Langhoff-Roos J, Kristensen FB. Increased risk of preterm birth in women with cervical conization. Obstet Gynecol 1993;81(6):1005-1008 
2 Iams JD. Cervical insufficiency. In: Creasy RK, Resnik R, Iams JD, Lockwood CJ, Moore TR, eds. Creasy and Resnik's Maternal-Fetal Medicine: Principles and Practice. 6th ed. Philadelphia, PA: Elsevier Inc; 2009:586

3 Ferenczy A, Choukroun D, Falcone T, Franco E. The effect of cervical loop electrosurgical excision on subsequent pregnancy outcome: North American experience. Am J Obstet Gynecol 1995;172(4 Pt 1):1246-1250

4 Albrechtsen S, Rasmussen S, Thoresen S, Irgens LM, Iversen OE. Pregnancy outcome in women before and after cervical conisation: population based cohort study. BMJ 2008;337:a1343

5 Kyrgiou M, Koliopoulos G, Martin-Hirsch P, Arbyn M, Prendiville W, Paraskevaidis E. Obstetric outcomes after conservative treatment for intraepithelial or early invasive cervical lesions: systematic review and meta-analysis. Lancet 2006;367(9509):489-498

6 Arbyn M, Kyrgiou M, Simoens C, et al. Perinatal mortality and other severe adverse pregnancy outcomes associated with treatment of cervical intraepithelial neoplasia: meta-analysis. BMJ 2008;337: a1284

7 Himes KP, Simhan HN. Time from cervical conization to pregnancy and preterm birth. Obstet Gynecol 2007;109(2 Pt 1):314-319

8 Koyama S, Tomimatsu T, Kanagawa T, Sawada K, Tsutsui T, Kimura T. Cervical insufficiency following cesarean delivery after prolonged second stage of labor: experiences of two cases. J Obstet Gynaecol Res 2010;36(2):411-413

9 Vyas NA, Vink JS, Ghidini A, et al. Risk factors for cervical insufficiency after term delivery. Am J Obstet Gynecol 2006; 195(3):787-791

10 Peleg D, Perlitz Y, Pansky S, Levit A, Ben-Ami M. Accidental delivery through a vaginal incision (laparoelytrotomy) during caesarean section in the second stage of labour. BJOG 2001; 108(6):659-660

11 Sung JF, Daniels KI, Brodzinsky L, El-Sayed YY, Caughey AB, Lyell DJ. Cesarean delivery outcomes after a prolonged second stage of labor. Am J Obstet Gynecol 2007;197(3):306.e1-306.e5

12 Harger JH. Cervical cerclage: patient selection, morbidity, and success rates. Clin Perinatol 1983;10(2):321-341

13 Melamed N, Ben-Haroush A, Chen R, Kaplan B, Yogev Y. Intrapartum cervical lacerations: characteristics, risk factors, and effects on subsequent pregnancies. Am J Obstet Gynecol 2009; 200(4):388.e1-388.e4

14 Smith DH, Kirsop R. Cervical incompetence occurring after caesarean section: a case report. Asia Oceania J Obstet Gynaecol 1991; 17(3):225-226

15 American College of Obstetricians and Gynecologists. ACOG Practice Bulletin No. 101: ultrasonography in pregnancy. Obstet Gynecol 2009;113(2 Pt 1):451-461

16 American College of Obstetricians and Gynecologists. ACOG Practice Bulletin No.142: cerclage for the management of cervical insufficiency. Obstet Gynecol 2014;123(2 Pt 1):372-379

17 Esplin MS, O'Brien E, Fraser A, et al. Estimating recurrence of spontaneous preterm delivery. Obstet Gynecol 2008;112(3):516-523

18 Bakketeig LS, Hoffman HJ. Epidemiology of preterm birth: results from a longitudinal study of births in Norway. In: Elder MG, Hendricks CH, eds. Preterm Labor. London: Butterworths; 1981

19 Martin JA, Hamilton BE, Ventura SJ, Osterman MJK, Mathews TJ. Births: final data for 2011. Natl Vital Stat Rep 2013;62(1):1-69, 72

20 ACOG Committee on Practice Bulletins - Obstetrics. ACOG Practice Bulletin No. 107: induction of labor. Obstet Gynecol 2009; 114(2 Pt 1):386-397 